\title{
Yatar Gövdeli Demiryolu Araç Teknolojisi ve Türkiye
}

\author{
Fatih YILDIZHAN@ \\ Gaziantep Üniversitesi, Müh. Fak., İnşaat Mühendisliği Bölümü, 27310, Gaziantep, Türkiye
}

fyildizhan@gantep.edu.tr

(Alınıs/Received: 09.05.2020, Kabul/Accepted: 01.07.2020, Yayımlama/Published: 31.07.2020)

\begin{abstract}
Öz: Türkiye'de Cumhuriyet'in ilk yıllarında demiryolunun yolcu taşımacıllğındaki payı \% 42, yük taşımacılığında payı \%68 iken, yapılan karayolu ağırlıklı yatırımlar sebebiyle 2003 yılında demiryolunun yolcu taşımacilığında payı \%2,7'ye, yük taşımacıllğında payı \%5,1'e düşmüştür. 2003 yılından itibaren yüksek hızlı tren (YHT) projeleriyle demiryolu için yeni dönem başlamış ve $1213 \mathrm{~km}$ YHT hattı tamamlanmıştır. YHT hatlarının uzun sürede tamamlanması, bütün güzergâhlarda uygulanabilir olmaması, maliyetlerinin yüksek olması ve 2019 yılına gelindiğinde Türkiye'de demiryolunun yolcu ve yük taşımacılığındaki payının azalması, TCDD tarafından hazırlanan 2019-2023 stratejik planında konvansiyonel hatların hizmetlerinin geliştirilmesinin hedeflenmesi, dünya üzerinde birçok örneği olan yatar gövdeli demiryolu araç teknolojisinin Türkiye'de uygulanabilirliğini akla getirmiştir. Sahip olduğu eğilme teknolojisi sayesinde yatay kurplarda $8^{\circ}$ ye kadar eğilebilmesiyle \%20-25 daha hılı hizmet veren yatar gövdeli demiryolu araç teknolojisi birçok ülkede uzun yıllardır kullanılmaktadır. Yüksek maliyetli altyapı ve üstyapı değişikliği gerektirmeden sadece hat üzerinde bazı iyileștirmelerle bu teknoloji kullanılabilir. Bu teknoloji Türkiye'de konvansiyonel hatlara düşük yatırım maliyetleriyle kısa sürede uygulanabilir. Yapılan hesaplamalara göre Türkiye'de uygulanması durumunda demiryolunun yolcu taşımacilığındaki hedeflerine katkıda bulunabileceği ve ulusal ekonomiye ciddi faydalar sağlayabileceği düşünülmektedir.
\end{abstract}

Anahtar kelimeler: Yolcu taşımacıllı̆ı, Demiryolu, Yatar gövdeli demiryolu aracı

\section{Tilting Train Technology and Turkey}

\begin{abstract}
The share in the republic's railway passenger transport in the early years in Turkey $42 \%$, while its share in freight transportation was $68 \%$, in 2003 , the share of passenger rail $2.7 \%$, the share of freight transport has fallen to $5.1 \%$, due to highway investments. Since 2003, a new period for the railway has started with the high-speed rail (HSR) projects and the $1213 \mathrm{~km}$ HSR line has been completed. Completion of HSR lines in a long time, not applicable on all routes, high costs and reduction of the share of rail passenger and freight transport in Turkey when it comes to 2019, aiming to improve the services of conventional lines in the 2019-2023 strategic plan prepared by TCDD, the applicability of the tilting train technology which has many examples around the world came to mind in Turkey. Thanks to its tilting technology, it can be tilted up to $8^{\circ}$ in horizontal curves and it provides $20-25 \%$ faster service, this technology has been used for many years. This technology can only be used with some improvements on the line without requiring costly infrastructure and superstructure changes. In Turkey, this technology can be applied to conventional lines in a short time with low investment costs. According to calculations, in case of implementation of the tilting technology in Turkey could contribute to the objectives of rail passenger transport and is expected to provide substantial benefits to the national economy.
\end{abstract}

Keywords: Passenger transportation, Railway, Tilting train.

\section{Giriş}

Ulaşım, insanların ve eşyaların belirli bir amaç için yer değiştirmesidir. Bu yer değiştirmenin sağlanmasına ulaştırma veya taşıma denir. Ulaştırma insanların en temel ihtiyaçlarından biridir [1]. Ulaştırma; ekonomik, sosyal, kültürel ve diğer sektörlerin tamamına etki eder [2]. Ulaştırma 


\section{Demiryolu Mühendisliği}

hizmetinin güvenli, ekonomik, konforlu, düzenli ve hızlı olarak sağlanması gerekir. Fakat bir ulaştırma türünün bütün özellikleri yüksek standartlarda bünyesinde bulundurması oldukça zordur. Ulaştırma türlerinin sinıflandırılması Şekil 1'de verilmiştir. Her türün zayıf ve üstün yanları bulunmaktadır [3].

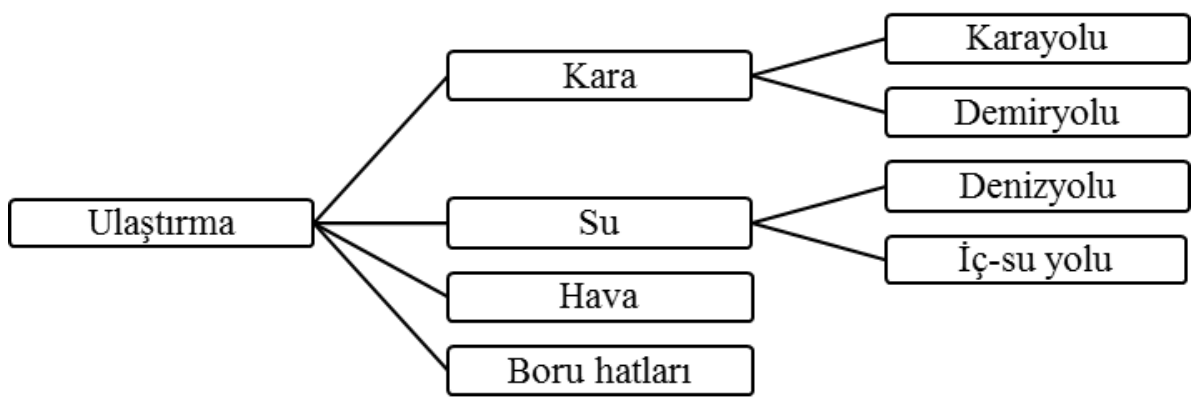

Şekil 1. Ulaştırma Türleri [4]

Ulaştırma türleri değerlendirilirken, hız, kapasite, esneklik, yapım maliyetleri, işletme maliyetleri, çevresel kriterler ve enerji tüketimi gibi birçok kriterin göz önünde bulundurulması gerekir [1]. Bu kriterlerin önceliği kullanım amacı (yolcu-yük veya sosyal-ekonomik) ile ülkenin teknolojik ve mali gücüne göre değişir [3]. Bu husustaki en önemli nokta ulaştırma türlerinin gelişmiş, sürdürülebilir ve birbiriyle entegre biçimde olmasıdır [5]. Herhangi bir ulaşım türüne ağırlık vermekle yüksek standartlarda ulaşım hizmeti verilmesi oldukça zordur [6].

Avrupa Birliği (AB) Ülkeleri tarafından imzalanan 1957 Roma Antlaşmasıyla ulaştırma sektörü pazarlarının entegre edilmesi, tekellerin engellenmesi ve ulaştırma sistemlerinin iyileştirmesi gibi birçok karar alınmıştır [7]. Fakat demiryolu taşımacılığı bu antlaşmadan yeterli düzeyde yararlanamamıştır. Her ülkenin farklı demiryolu sistemleri olmasından kaynaklanan uyumsuzluk buna sebep olmuştur [7]. Dünyada teşviklerle beraber karayolu payının artması, trafik sıkışıklığı, gürültü, çevre kirliliği ve kaza kaynaklı kayıplar gibi birçok olumsuzluğu beraberinde getirmiştir [8]. 1990'lı yıllarda Avrupa'da demiryolları hatlarının yaşlanmış olması, düşük işletme hızı ve havayolu ulaşımıyla rekabet gibi sebeplerden demiryolu kullanım payı azalmıştır [7]. 1990'1 yıllardan itibaren gerçekleşen demiryolu reformuyla uyumlaştırma, altyapısal değişiklikler ve 250 $\mathrm{km} / \mathrm{sa}$ üzerinde hız yapan yüksek hızlı demiryolu projeleri yapılmaya başlanmıştır $[7,8]$. Son yıllardaki istatistikler incelendiğinde ulaşım türlerine göre ABD'de taşımacılı̆̆ın \%27'si karayolu, \%38'i ise demiryolu kullanılarak yapılmış, Almanya'da ise bu oranlar sırasıly $\% 58$ ve $\% 22$ değerlerini almıştır [6]. Ayrıca demiryolu uzunluklarına bakıldı̆̆ında ABD demiryolu uzunluğu $226.706 \mathrm{~km}$, Almanya demiryolu uzunluğu ise 48.215 km'dir [9].

Türkiye'de demiryolu ulaşımı 1856'da yapımına başlanan İzmir-Aydın hattı ile başlamıştır [10]. Demiryolu ulaşımının ilk kez 1825 yılında Stockton-Darlington arasında başladığ düşünüldüğünde yatırım konusunda çok geç kalınmadığ 1 söylenebilir [11]. Osmanlı İmparatorluğu'nun son dönemlerinde demiryolu taşımacılığ en önemli taşımacılık modeli olmuş ve karayolu, demiryolunu tamamlayan faktör olarak görülmüştür. Demiryolu taşımacılığında en çok yatırım Sultan II. Abdulhamit döneminde ve Cumhuriyetin ilk yıllarında yapılmıştır [10]. Bu yıllarda demiryolunun yolcu taşımacılığındaki payı $\% 42$, yük taşımacılığındaki payı ise $\% 68$ 'dir [10]. Ancak, 1950 yılında ABD'nin Marshall yardımıyla tamamen karayolu ağırlıklı politikalar izlenmiştir. Bu yıllarda y1llık ortalama 39 km'lik konuma demiryolu inşa edilmiş [6] ve 2003 yılında demiryolunun yolcu taşımacılığındaki payı \%2,7, yük taşımacılığındaki payı ise $\% 5,1$ 'e düşmüş, karayolunda ise bu paylar sırasıyla \%95,7 ve \%88,9'a yükselmiştir [12]. Türkiye'de demiryolu yatırımlarının zamanında yapılmamış olması sebebiyle yük ve yolcu taşımacılığında karayolunun payı çok yüksektir [2]. Demiryolu ve karayolu ulaşımında yapım, bakım ve işletme maliyetleri göz önünde bulundurulduğunda demiryollarının yolcu taşımacılığında \%40-50 


\section{Demiryolu Mühendisliği}

oranında, yük taşımacıllığında ise yaklaşık \%70 oranında daha ucuz olduğu tespit edilmiştir [13]. $\mathrm{Bu}$ sonuçlar demiryollarının ihmal edildiği politikaların ve bunun sonucunda demiryolu payının azalmasının yanlış olduğunu göstermektedir.

Türkiye'de demiryolu ulaşımında yeni dönem 2003 yılında başlamıştır. $10.948 \mathrm{~km}$ uzunluğa sahip olan ve ikinci planda kalan demiryolu ulaşımına yeniden önem verilmeye başlanmıştır. 2009 yılında Ankara-Eskişehir, 2011 yılında Ankara-Konya ve 2014 yılında Eskişehir-İstanbul hızlı/yüksek hızlı tren (YHT) hatları tamamlanmıştır. Böylece $1.213 \mathrm{~km}$ YHT hattı yapılmış ve demiryolu hattı uzunluğu toplam 12.740 km'ye çıkmıştır [14]. Ankara - İzmir, Ankara - Sivas, Ankara - Bursa YHT hatlarında çalışmalar devam etmektedir. Türkiye 2023 y1lı hedefleri doğrultusunda toplam $17.500 \mathrm{~km}, 2035$ y1lında ise toplam $30.000 \mathrm{~km}$ demiryolu hattı uzunluğuna sahip olunması hedeflenmektedir [15,16]. 2023 yılında demiryolu payının; yolcu taşımacılığında $\% 3,8$ ve yük taşımacılığında ise $\% 10$ 'a, 2035 yılında ise bu payların sırasıyla $\% 15$ ve $\% 20$ 'ye çıkarılması hedeflenmektedir $[15,16]$.

Demiryolu ulaştırması ülkeler için gelişmişlik sembolü olarak gösterilmektedir [17]. Bu anlamda demiryolunun Türkiye'de payının artırılmasına yönelik hedefler doğrudur. Karayolunun payının azaltılması, ulaşım türlerinde entegrasyonun sağlanması açısından önemli hedeflerdir. Fakat yapılan 16 yıllık yatırımlara rağmen demiryolu payının yolcu ve yük taşımacılığında artmaması üzerinde düşünülmesi gereken bir konudur. 2003 yılında demiryolu yolcu taşımacıllğının payı $\% 2,7$ iken, 2019 yılında azalarak \%1 olmuş, yük taşımacılığındaki payı ise 2003 yılında \%5,1 iken, 2019 yılında \%4,5'e düşmüştür $[12,16]$.

Demiryolunun alt ve üst yapısının kalitesi, geometrik standartları göz önüne alındığında:

1. Konvansiyonel hatlar: $160 \mathrm{~km} / \mathrm{sa}$ hızlara ulaşabilen yollar,

2. Hızlı demiryolu hatları: $160-250 \mathrm{~km} / \mathrm{sa} \mathrm{hızlara} \mathrm{ulaşabilen} \mathrm{yollar,}$

3.Yüksek hızlı demiryolu hatları (YHT): $250 \mathrm{~km} / \mathrm{sa}$ 'den fazla hız yapabilen yollar olarak tanımlanmaktadır [5]. YHT, 400-700 Km arasındaki mesafelerde daha çok tercih edilmekte, mesafe arttıkça tercih havayoluna geçmektedir [8]. Fransa'da yapılan yüksek hızlı demiryolu arac1 yatırımları Paris-Lyon arasında istenilen sonucu vermiş ve neticesinde diğer büyükşehirler de bu yatırımları talep etmiştir. Fakat yapılan 6 yatırımın istenilen sonucu vermediği, demiryolu araçlarının hattın \%40'nda normal hızlarda ilerlediği ve bu yüzden YHT yatırımlarının 2030 yılına kadar ertelendiğini duyurmuştur [8].

Türkiye'de 2003 yılından itibaren demiryolu kullanım payını artırmaya yönelik yapılan yatırımların istenilen düzeyde sonuç vermemesi, yüksek hızlı demiryolu hattı yatırımlarının yüksek maliyeti (örneğin Ankara-Eskişehir hattının ortalama km yapım maliyeti 9.506.472,49 TL [18]) ve işletme hızının çok yüksek olmaması (örneğin Ankara-Eskişehir $184 \mathrm{~km} / \mathrm{sa}$ [18]) gibi sonuçlar, bunlara ek olarak 2019-2023 TCDD stratejik hedeflerinde konvansiyonel hatların hizmetlerinin geliştirilmesi ve daha cazip hale getirilmesinin planlanması, demiryolu kullanım payını artırmaya yönelik başka projeler üzerinde düşünülmesi gerektiğini göstermektedir.

Demiryolu hızını artırmanın iki yolu bulunmaktadır. Birincisi hattın yüksek hızlı demiryolu veya hızlı demiryolu standartlarına uygun olacak şekilde altyapı ve üstyapının yeniden inşa edilmesidir. Bu yöntem oldukça pahalıdır. İkinci yöntem ise mevcut altyapı üzerinde demiryolu araçlarının gövdelerinin yatmasıyla \%20-25 aralığında hızını artırmasıdır [19]. 1930'lu yıllarda tasarımına başlanan bu teknoloji yatar gövdeli demiryolu aracı (tilting train) olarak adlandırılmaktadır. Yatar gövdeli demiryolu araç sistemi, demiryolu aracı hızını artırmanın en efektif yoludur [20]. Japonya'da 1973 yllından beri bu teknolojiyle hizmet veren demiryolu araçları bulunmaktadır [21]. Bu teknoloji İtalya, İspanya, Almanya, İsveç ve İngiltere gibi birçok ülkede kullanılmaktadır [19]. 


\section{Demiryolu Mühendisliği}

Bu çalışmada yatar gövdeli demiryolu araç teknolojisi ve sahip oldukları eğilme sistemlerinin detayları incelenmiş, yapılması durumunda dikkat edilecek konular belirtilmiştir. Türkiye'de bulunmayan ve şuan projesi düşünülmeyen yatar gövdeli demiryolu araç teknolojisinin Türkiye'de uygulanabilirliği incelenmiş ve ülkeye sağlayacağ 1 katkılar belirtilmiştir. Ekonomik faydalar açısından konvansiyonel hatların yatar gövdeli demiryolu araç teknolojisine dönüştürülmesiyle oluşacak zaman tasarrufu ve bunun ekonomik değeri farklı senaryolara göre hesaplanmıştır.

\section{Yatar Gövdeli Demiryolu Aracı}

Yatar gövdeli demiryolu araçları, ray üzerinde hareket ederken, yatay kurplarda meydana gelen merkezkaç kuvvetinin etkisini minimize etmek için yatay kurp doğrultusunda eğilebilen demiryolu araçlarıdır [22]. Demiryolu araçlarında iki tekerlek ve bir aks, araç altındaki bojilere monte edilir [23]. Bojiler araç gövdesini taşımak ve dengeyi sağlamak zorundadır. Yatar gövdeli demiryolu araçlarının bojileri yanal kuvvetleri minimize etmek için en önemli elemanlardır [22]. Konvansiyonel hattaki demiryolu aracında $160 \mathrm{~km} / \mathrm{sa}$ hızla gidilen yatay kurpta yanal kuvvet 70 $\mathrm{N}$ iken, yatar gövdeli demiryolu aracında aynı kurpta $240 \mathrm{~km} / \mathrm{sa}$ ile gidilirken yanal kuvvet 22 N'dir. Şekil 2'de yatay kurplardaki yanal kuvvet etkisi gösterilmiştir [24].

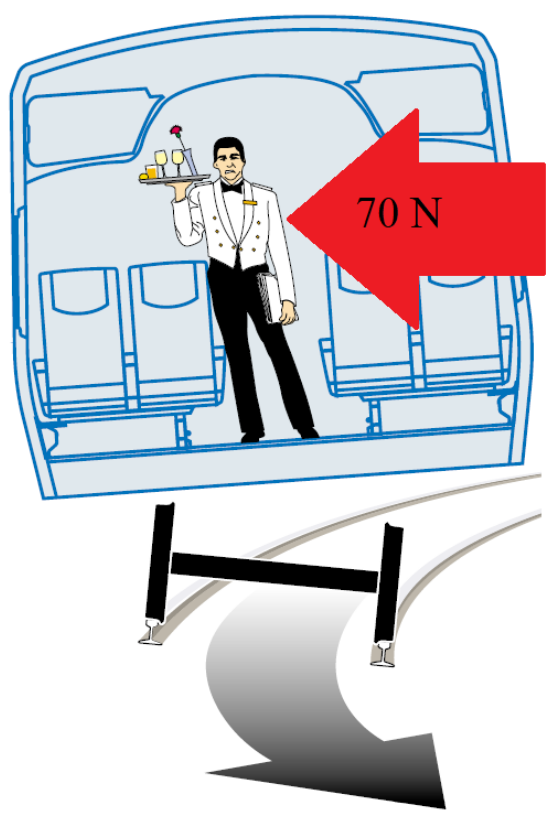

a)

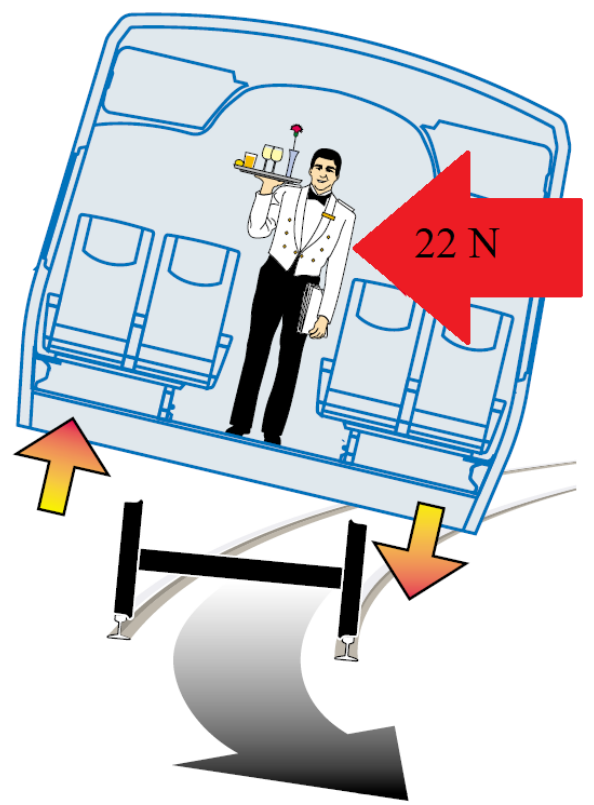

b)

Şekil 2. Yatay kurplardaki a) normal demiryolu aracı b) Yatar gövdeli demiryolu aracı [24]

Yatar gövdeli demiryolu araçlarının eğilme sistemi; eğimli aktüatör, eğimli beşik travers ve eğimli bağlantılardan oluşur. Yatar gövdeli demiryolu aracı eğilme sistemi Şekil 3'te verilmiştir. Araç gövdesi, hava yayıyla eğimli beşik travers üzerine oturur. Yatay kurplarda, boji şasisi ve eğimli beşik travers arasına yerleştirilen eğimli aktüatörden kaynaklı momentle araç gövdesi eğilir [22]. 


\section{Demiryolu Mühendisliği}

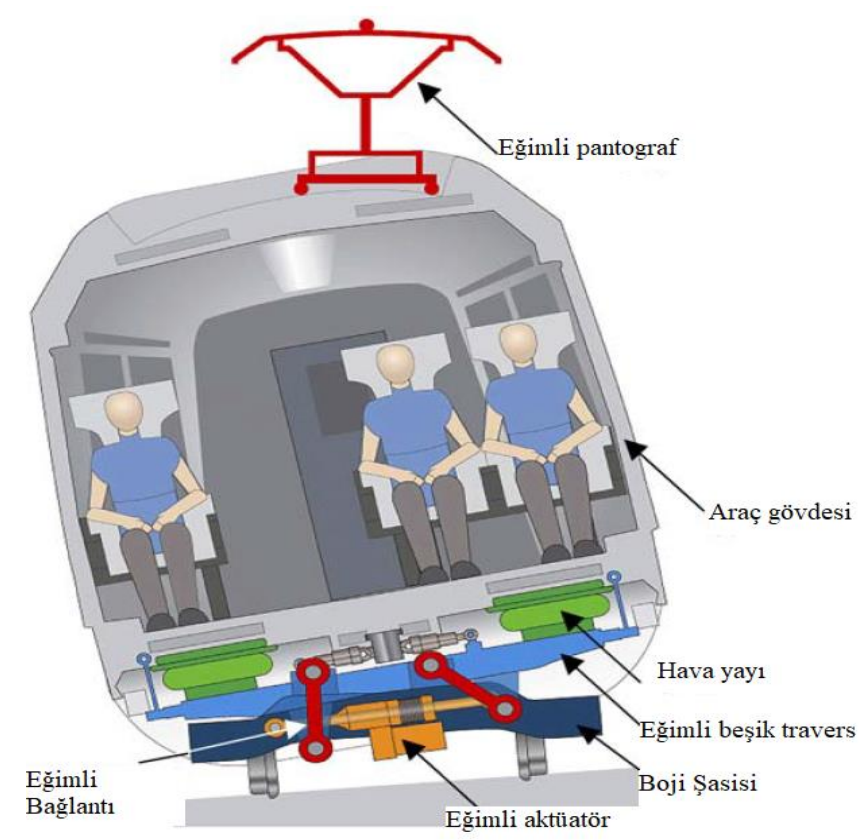

Şekil 3. Yatar gövdeli demiryolu aracı eğilme sistemi [19]

Yatar gövdeli demiryolu araçlarında eğilme sistemine etki eden, araç gövdesi ağırlığı ve aktüatörden kaynaklı kuvvetler ve bu kuvvetlerin bileşkesi Şekil 4'te verilmiştir. Eğilme sistemleri, yatay kurplarda dönüş yönüne doğru maksimum 8 derece eğilebilecek şekilde tasarlanmaktadır [20].

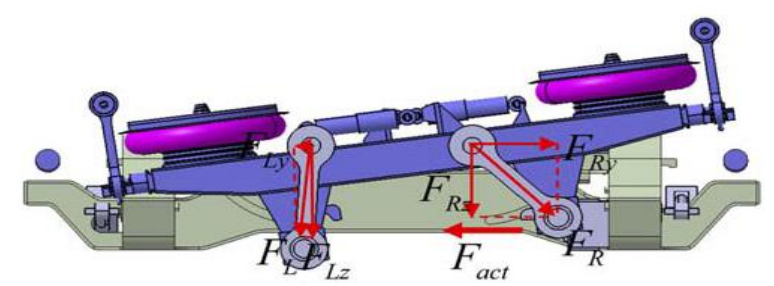

a)

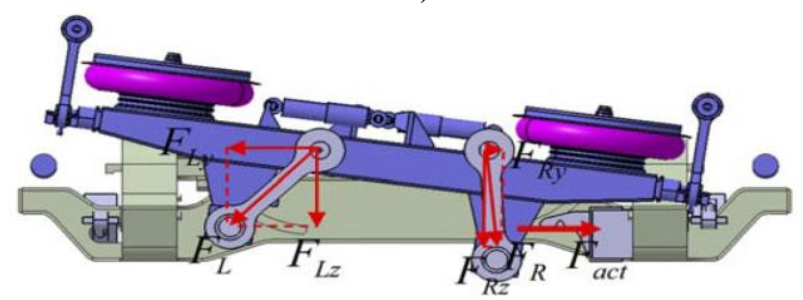

b)

Şekil 4. a) -8 derecede b) +8 derecede eğilme sistemindeki bileşke kuvvetler [19]

Güney Kore'de yatar gövdeli demiryolu aracı AR-GE projeleri 2001 yılında başlamış, 2006 yılında prototipi oluşturulmuş ve 2007 yılında test sürüşleri başlamıştır [25]. Türkiye'de raylı ulaşımda yerli üretim yapan firmalarımız Güney Kore'de olduğu gibi kısa sürede yatar gövdeli demiryolu aracı üretebilir. 5-6 yıl içinde üretilebilecek yerli yatar gövdeli demiryolu araçları ve hatlarda yapılan iyileştirmelerle kısa sürede Türkiye'nin tüm bölgelerinde daha kaliteli demiryolu taşımacılığı hizmeti verilebilir. Özellikle dağlık arazilerde YHT projelendirilmesi yatay kurp kısıtlamalarından dolayı zor ve maliyetleri yüksek olacaktır. YHT için harcanan yüksek maliyetlerin yatar gövdeli demiryolu araçlarına kaydırılması çok daha hızlı, ekonomik ve başarılı sonuçlar verebilir. 


\section{Demiryolu Mühendisliği}

\subsection{Yatar gövdeli demiryolu aracı teknolojisi için dikkat edilmesi gereken konular}

Konvansiyonel demiryolu hatlarının yatar gövdeli demiryolu araçlarının kullanımına uygun demiryolu hatlarına dönüştürmek için bazı konuların dikkate alınması gerekir. Mevcut hat daha hızlı hizmet vereceği için hat bileşenlerinin durumu oldukça önemlidir [26]. Dikkate alınması gereken konular şu şekilde sıralanabilir:

- Pantograf-katener etkileşimi: Yatar gövdeli demiryolu araçlarının konvansiyonel demiryolu araçları ile aynı katener hattını kullanmasından dolayı yatar gövdeli demiryolu araçlarındaki pantografta daha fazla dinamik kuvvet oluşmaktadır. Pantograftaki yatay yer değiştirme konvansiyonel hatta göre $50 \mathrm{~cm}$ 'yi aşabilir. Bu anlamda yatay yer değiştirme belirli sınırlar içinde kalmalıdır [20].

- Travers: Traverse gelen kuvvet kaynaklı etki ahşap traverslerde betonarme traverslere göre \%21-23 oranında fazladır [26]. Konvansiyonel hatlarda bulunan ahşap traversler değiştirilmelidir.

- Yatay kurp: Dar yatay kurplarda demiryolu araçları kuvvetlerinin etkisi geniş yatay kurplara göre fazladır. Yatay kurp 400 m'den 600 m'ye çıktı̆̆ında hatta \%17-18 daha az kuvvet gelmektedir [26]. Bu yüzden dar kurp noktalarına dikkat edilmelidir. Gerekli yerlerde farklı yatay kurp tasarımı yapılabilir.

- Geçiş Eğrisi: Aliymandan yatay kurba geçişteki merkezkaç etkisini azaltmak için geçiş eğrisi kullanılmalıdır. Uzun geçiş eğrilerinin yapılması hatta etki ve yolcu konforu açısından uygulanmalıdır. Geçiş eğrileri olmadan yapılan yatay kurplar yatar gövdeli demiryolu araçlarının avantajını azaltmaktadır [27].

- Titreşim: Demiryolu araçlarından kaynaklı titreşimin çevreye olumsuz etkisini engellemek için titreşim belirli sınırlar içinde tutulmalıdır [28].

- Yolcu konforu: Yol tutması yatar gövdeli demiryolu aracını kullanan yolcular için temel problemlerden biridir. Yatay eğim açısı ve hız arttıkça yolcuların konfor seviyesi düşmektedir [29]. Demiryolu hızını artırırken yolcuların konforu da dikkate alınmalıdır.

- Rüzgâr etkisi: Rüzgâr etkisinden kaynaklı stabilite hesapları çok dikkatli yapılmalıdır [21]. Gereken yerlerde rüzgâr bariyerleri kullanılmalıdır.

- Bakım-onarım maliyetleri: Yatar gövdeli demiryolu araçlarının hareketli ekipmanlarının fazla olması sürtünme ve aşınma kaynaklı bakımları arttırmaktadır [18].

Ayrıca hat üzerinde özel düzenlemeler gerektirmese de balast, ray ve ray bağlantılarına gerekli iyileştirmeler yapılmalıdır [27]. Kore'de hizmet veren yatar gövdeli demiryolu aracı ciddi zaman tasarrufu sağlamıştır. Fakat bunun çoğunluğu hat iyileştirmeden kaynaklıdır. Özellikle dar kurpların daha büyük yarıçaplı kurplara dönüştürülmesi çok önemlidir [25].

\section{Metot}

Ulaştırma projelerinin değerlendirilmesi, mali ve ekonomik fizibilite etüdü olarak ikiye ayrılmaktadır. Mali fizibilite etüdü, projenin yatırımcı/işletmeci kuruluş açısından değerlendirilmesidir. Ekonomik fizibilite etüdüyse projenin ulusal ekonomi açısından değerlendirilmesidir. Ekonomik fizibilite etüdünde herhangi bir projenin yapılması ve yapılmaması durumundaki fayda-maliyetler hesaplanarak projenin uygulanabilirliği incelenmektedir. Yatar gövdeli demiryolu araç teknolojisinin yapılması durumundaki fayda ve maliyetler Şekil 5'de verilmiştir. 


\section{Demiryolu Mühendisliği}

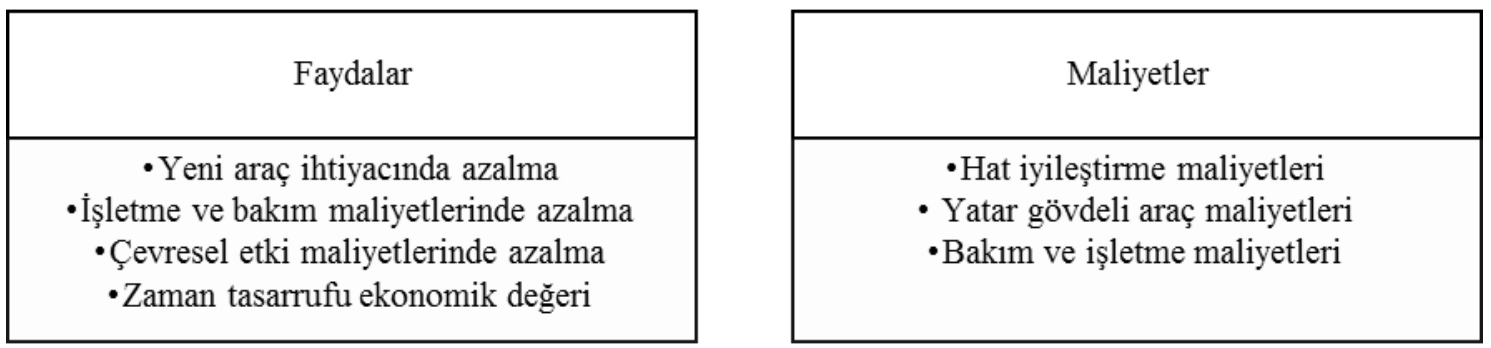

Şekil 5. Yatar gövdeli demiryolu araç fayda ve maliyetleri

Yatar gövdeli demiryolu araçlarıyla çok daha kısa sürede, çok daha az maliyetle daha hızlı ulaşım sağlanabilir. İşletme hızının artması, aynı zamanda hat üzerinde çalışan demiryolu aracı setlerinin daha fazla sefer yapmasına imkân verecek ve sefer sayısının artmasıyla kapasite arttırılmış olacaktır [30]. Kapasite artırılması gereken güzergâhlarda demiryolu aracı setlerinin alımı azalacaktır. Bu yüzden araç yatırımı konusunda avantaj sağlayacaktır.

Yatar gövdeli demiryolu araçları daha kısa süre yol aldığ 1 için işletme ve bakım maliyetlerinde, enerji kayıpları ve süre azaldığı içinde çevresel etki maliyetlerinde azalma sağlanacaktır. Fakat hız arttığı için enerji maliyetleri artacaktır.

Ulaştırma projelerinde dikkate alınması gereken en önemli parametre zaman tasarrufudur. Yapılan fizibilite etüdlerinde ekonomik değeri en yüksek parametredir [1]. Herhangi bir projenin yapılması ve yapılmaması durumundaki zaman farkının, yolcu sayısı ve yolculuk zaman değeriyle çarpılmasıyla elde edilir [1].

Zaman değeri hesaplamaları Tablo 1'de verilmiştir. Yolculuk zaman değerinin hesaplanmasında Eskişehir 2019 Gayri safi yurtiçi hasıla (GSYIH) verileri kullanılmıştır. Eskişehir verilerine göre yıllık ortalama çalışma günü sayısı 266 ve çalışma saati toplamı 2130 olarak alınmıştır. Çalışan nüfus oranı 0,28 ve iş yolculuklarının toplam yolculuklara oranı 0,2868 'dir [1].

Tablo 1. Zaman değeri [1]

\begin{tabular}{lc}
\hline Kişi başına GSYİH & $3779,52 \$$ \\
Çalışan kişi başına GSYİH & $13866,60 \$$ \\
Çalışma saati zaman değeri (saat) & $6,51 \$$ \\
Ortalama zaman değeri & $3,03 \$$ \\
\hline
\end{tabular}

Yolcu başına ortalama zaman değeri farklı şehirlere göre değişebileceği için bu değerlerin \%20 fazla ve $\% 20$ az olduğu değerler de dikkate alınmıştır. Yolcu başına ortalama zaman tasarrufu; hattın uzunluğuna, güzergâhın arazi yapısına, yapılan iyileştirmelere göre kazanılacak ekstra hız (max \%25), yolculuk talebi gibi değerlere göre değişmektedir. Bu yüzden yolcu başına ortalama $10,20,30,40 \mathrm{dk}$ alınarak hesaplamalar yapılmıştır.

\section{Bulgular}

Yatar gövdeli demiryolu araç teknolojisi için öncelikle mevcut hat bileşenlerinde bazı iyileştirmeler yapılmalıdır (Bknz 2.1). Fakat bu iyileştirmeler tüm güzergâh boyunca değil, uygun standartta olmayan ve kritik olan noktalarda olacaktır. Hattın iyileştirilmesi için yapılacak olan uygulamalar ekstra maliyetler getirecektir. Ayrıca yatar gövdeli demiryolu araç teknolojisine sahip setler de belirli maliyetler getirecektir. Ancak, bu iyileştirme ve yeni teknoloji çok kısa sürede ve YHT'ye göre çok daha az maliyetle uygulanabilmektedir.

Yatar gövdeli demiryolu aracının Türkiye'de konvansiyonel hatlarda yapılması durumunda (ortalama değerlere göre \%20-25) daha hızlı hizmet vermesi sayesinde zaman tasarrufu 


\section{Demiryolu Mühendisliği}

sağlanacaktır. Yolculuk süresinin kısalması yolculuk talebini de arttıracaktır. Farklı senaryolara göre yolcu başına ortalama süre tasarrufu ve ortalama zaman değerlerine göre zaman tasarruf değeri Tablo 2'de verilmiştir. 2018 yılında konvansiyonel hatlarda 16.185 .000 yolcu taşınmıştır [14]. Tüm konvansiyonel hatların yatar gövdeli demiryolu araçlarının kullanıma uygun inşa edilmesi durumunda, güzergâh ve yolcu sayısına bağlı olmakla beraber yolcu başına ortalama 1020-30-40 dk gibi farklı senaryolara göre tasarruf sağlandığg düşünülerek hesaplamalar yapılmıştır. Ortalama zaman değeri Eskişehir verilerine göre 3,03 \$ alınmıştır. Farklı şehirlerde bu değer değişebileceği için $\% 20$ fazla ve $\% 20$ az olarak alındığı hesaplamalar da göz önünde bulundurulmuştur.

Tablo 2. Farklı senaryolara göre yıllık zaman tasarruf değeri

\begin{tabular}{cccccc}
\hline $\begin{array}{c}\text { Ortalama zaman değeri/ } \\
\text { Ortalama zaman tasarrufu }\end{array}$ & $10 \mathrm{dk}$ & $15 \mathrm{dk}$ & $20 \mathrm{dk}$ & $30 \mathrm{dk}$ & $40 \mathrm{dk}$ \\
\hline Zaman değeri $(3,03 \$)$ & $8173425 \$$ & $12260138 \$$ & $16346850 \$$ & $24520275 \$$ & $32693700 \$$ \\
Zaman değeri \%20 fazla & $9818900 \$$ & $14728350 \$$ & $19637800 \$$ & $29456700 \$$ & $39275600 \$$ \\
Zaman değeri \%20 az & $6527950 \$$ & $9791925 \$$ & $13055900 \$$ & $19583850 \$$ & $26111800 \$$ \\
\hline
\end{tabular}

Hattın iyileştirilmesiyle yük taşımacılığı da çok daha hızlı şekilde yapılacaktır. Bu sayede demiryolunun yük taşımacılığındaki payı artacaktır. Ayrıca demiryolu araçlarının daha az süre hareket etmesi, yatay kurplardan önce daha az fren yapması, enerji kayıplarını, enerji maliyetlerini ve enerji kaynaklı çevresel maliyetleri azaltacaktır. Bu yüzden, yatar gövdeli demiryolu aracı teknolojisi yapılan yatırımları 5-6 y1l içinde geri ödeyebilir [31]. Konvansiyonel hatlarda kullanılan Alstom firmasının "Avelia Pendolino" ve Talgo firmasının "Talgo 250" eğilme teknolojili demiryolu araçları; güç kaynağı, sinyalizasyon sistemleri gibi farklılıklar nedeniyle uygulanabilirlik sorunlarına en iyi çözüm olarak gösterilmektedir. [31,32].

\section{Sonuç}

Gelişmiş demiryolu taşımacılığının olduğu nerdeyse tüm ülkelerde uzun yıllardır kullanılan yatar gövdeli demiryolu araç teknolojisinin Türkiye'de yapılması durumunda, sahip olduğu eğilme sistemi sayesinde demiryolu araçları yatay kurplarda merkezkaç kuvvetinin etkisini azaltarak \%20-25 daha hizlı gidebilir. Bu sayede konvansiyonel hatlardaki hizmet kalitesini arttırarak TCDD 2023 ve 2035 hedeflerini gerçekleştirebilir. Kurplardan önce daha az fren yapıldığı için enerji kayıplarını ve daha az süre yol alacağı için çevresel maliyetleri azaltabilir.

Türkiye'de büyükşehirlere demiryolu ulaşımının hızlı/yüksek hızlı trenle sağlandıktan sonra bu hatlara bağlantılarda ve mevcut konvansiyonel hatlarda yatar gövdeli demiryolu araç teknolojisinin kullanılması, kısa sürede ülke ekonomisine ciddi faydalar sağlayabilir. Konvansiyonel hatlarda yapılan bazı iyileştirmeler, istenilen seviyeye gelmeyen ve stratejik planda belirtilen demiryolu yük ve yolcu taşımacıllğının payını arttırabilir. Türkiye'de konvansiyonel hatların iyileştirilmesi sonrasında araçların, yatar gövdeli demiryolu araç teknolojisine dönüştürülmesi durumunda güzergâh konumuna ve standartlara bağlı olarak yıllık 6,5-39,3 milyon \$ arasında değişen zaman tasarrufu sağlanabilir. Ayrıca enerji ve çevresel maliyetlerin azalmasından kaynaklı tasarruflar da sağlanabilir.

İleride yapılabilecek çalışmalarda konvansiyonel hatların; yolcu sayıları, sefer sayıları, işletme hızı gibi veriler alındıktan sonra hattın geometrik tasarımları detaylıca incelenerek (özellikle yatay kurp) yatar gövdeli demiryolu aracına dönüştürülmesindeki zaman tasarrufu, çevresel maliyetler, araç maliyetleri, yapım maliyetleri detaylıca hesaplanıp ekonomik ve mali fizibilite etüdleri hazırlanabilir. 


\section{Demiryolu Mühendisliği}

\section{Kaynakça}

[1] F. Yıldızhan, "Monoray sisteminin Eskişehir'de uygulanabilirliğinin araştırılması,” Yüksek lisans tezi, İnşaat mühendisliği bölümü, Eskişehir Osmangazi Üniversitesi, Eskişehir, 2019.

[2] H. Aydemir, "Türkiye'nin ulaştırma politikaları çerçevesinde demiryolu ulaştırma sisteminin genel durumunun irdelenmesi ve geleceğine bakış," Demiryolu Mühendisliği, no. 3, pp. 41-46, 2016.

[3] N. Yayla, Karayolu Mühendisliği. İstanbul: Birsen Yayınevi, 2015.

[4] Ş. Bilgiç ve M. Karacasu, Karayolu Mühendisliği. Eskişehir: Osmangazi Üniversitesi, 2016.

[5] M. Orhan, Karayolu-Demiryolu Mühendisliği. Ankara: Gazi Kitabevi, 2019.

[6] M. Ç. Kızıltaş, Ülkemiz Ulaştırma Sistemi Üzerine Değerlendirmeler. İstanbul: Akıl Fikir Yayınları, 2016.

[7] Y. Uğurlu, “Avrupa birliğinde demiryolları,” Demiryolu Mühendisliği, no. 7, pp. 37-44, 2018.

[8] S. Yavuz, "Hızlı demiryolu aracı projelerine hız verilirken yük taşımacılığı ihmal ediliyor," Demiryolu Mühendisliği, no. 4, pp. 27-29, 2016.

[9] Ş. Bilgiç, "DEMIRYOLU," $2017 . \quad$ [Çevrimiçi]. Available: http://web.ogu.edu.tr/Storage/akalin/Uploads/demiryolu-dersnotu-1-2017.pdf. [Erişildi: 11 April 2020].

[10] İ. Pektaş, "Türkiye’de raylı ulaşım sistemlerinin gelişimi,” Demiryolu Mühendisliği, no. 5, pp. 8182, 2017.

[11] Darlington Borough Council and Stockton on Tees Borough Council., "The 1825 Stockton \& Darlington Railway: Historic Environment Audit," 2016. [Çevrimiçi]. Available: https://www.darlington.gov.uk/media/1944/2016-12-28-sdr-volume-1-significance management.pdf. [Erişildi: 08 June 2020].

[12] TCDD, "İstatistik Yıllı̆̆1-TCDD," 2014. [Çevrimiçi]. Available: http://www.tcdd.gov.tr/files/istatistik/20102014yillik.pdf. [Erişildi: 13 April 2020].

[13] A. Kabasakal ve A. O. Solak, "Demiryolu ve karayolu ulaştırma sistemlerinin ekonomik etkinlik analizi," Anadolu Üniversitesi Sosyal Bilimler Dergisi, vol. 10, no. 1, pp. 123-136, 2010.

[14] TCDD, "İstatistik Yıllı̆̆1-TCDD," 2019. [Çevrimiçi]. Available: http://www.tcddtasimacilik.gov.tr/uploads/images/Strateji/TCDD-T-2018-istatistik-yilligi.pdf. [Erişildi: 13 April 2020].

[15] ̇. Pektaş, "Ülkemizde raylı ulaşım sistemlerinin gelişimi ve arus," Demiryolu Mühendisliği, no. 4, pp. 68-70, 2016.

[16] TCDD, “2019-2023 Stratejik Plan,” 2019. [Çevrimiçi]. Available: http://www.tcddtasimacilik.gov.tr/uploads/images/Strateji/TCDD-Tasimacilik-2019-2023-

Stratejik-Plan.pdf. [Erişildi: 08 June 2020].

[17] Ç. Tabak, "Demiryolu ulaştırması ve emniyeti," Demiryolu Mühendisliği, no. 3, pp. 24-26, 2016.

[18] A. N. Yüce, "Ülkemizde planlanan, yapılmakta olan ve yapılan yüksek hızlı demiryolu hatlarının incelenmesi ve karşılaştırılması," Yüksek lisans tezi, İnşaat mühendisliği bölümü, İstanbul Teknik Üniversitesi, İstanbul, 2015.

[19] J. S. Kim, "Fatigue assessment of tilting bogie frame for Korean tilting train: Analysis and static tests," Engineering Failure Analysis, vol 8, no. 13, pp. 1326-1337, 2006.

[20] R. Luo, J. Zeng ve W. Zhang, "Pantograph Dynamics and Control of Tilting Train," Proceedings of the 17th World Congress The International Federation of Automatic Control, Seoul, Korea, 2008, pp.8293-8298.

[21] R. Persson, Tilting trains: Technology, benefits and motion sickness, Stockholm: Royal Institute of Technology (KTH) Aeronautical and Vehicle Engineering Rail Vehicles, 2008.

[22] J. S. Kim ve N. P. Kim, "Evaluation of structural safety of a tilting bolster," Engineering Failure Analysis, vol 1, no. 14, pp. 63-72, 2007.

[23] Y. Özdemir, "Ray-tekerlek temasında temas parametrelerinin incelenmesi," Demiryolu Mühendisliği, no. 11, pp. 1-13, 2020.

[24] B. Transportation, "Intercity Transport, High-Speed Trainsets," Bombardier Transportation, 2012. [Çevrimiçi].

Available: https://web.archive.org/web/20120515115623/http://www.traintesting.com/Acela_0029_Nov01_ en.pdf [Erişildi: 8 April 2020].

[25] H. L. Rho ve S. H. Han, "Running-time comparison of Tilting EMUs with Non-tilting trains on the Korean conventional railway, Jungang line," The 21st International Conference on Magnetically Levitated Systems and Linear Drives, Daejeon, Korea, 2011. 


\section{Demiryolu Mühendisliği}

[26] J. Choi, "Prediction of displacement induced by tilting trains running on ballasted tracks through measurement of track impact factors," Engineering Failure Analysis, no. 31, pp. 360-374, 2013.

[27] B. Kufver ve R. Persson, "Tracks for tilting trains - A study within the Fast And Comfortable Trains (FACT) project," 2013. [Çevrimiçi]. Available: http:/www.railwayresearch.org/IMG/pdf/ps.2.9.pdf. [Erişildi: 8 April 2020].

[28] T. Tadeusz ve K. Barbara, "The environmental impact of the vibration induced by the passage of trains at various speeds," Procedia Engineering, no. 199, p. 2693-2698, 2017.

[29] J. Förstberg, E. Andersson ve T. Ledın, "Influence of different conditions of tilt compensation on motion and motion-related discomfort in high speed trains," Vehicle System Dynamics, no. 29, pp. 729-734, 2007.

[30] O. Kılıç ve H. E. Beni, “Demiryollarında kapasite geliştirme,” Demiryolu Mühendisliği, no. 8, pp. 25-39, 2018.

[31] Alstom, “Avelia Pendolino: A high-speed favourite," Alstom, 2020. [Çevrimiçi]. Available: https://www.alstom.com/our-solutions/rolling-stock/avelia-pendolino-high-speed-favourite. [Erişildi: 20 April 2020].

[32] Talgo, "Rolling Stock / High Speed / 250," Talgo, 2020. [Çevrimiçi]. Available: https://www.talgo.com/en/rolling-stock/high-speed/250/. [Erişildi: 05 June 2020].

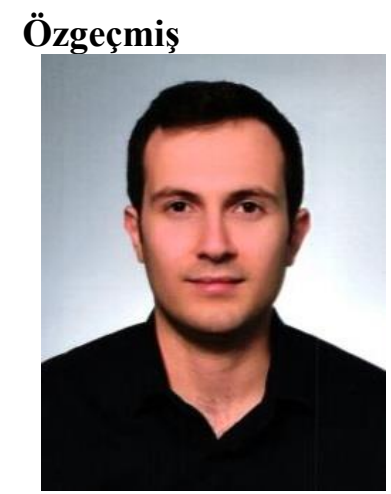

Beyanlar

\section{Fatih YILDIZHAN}

Lisans eğitimini Anadolu Üniversitesi inşaat mühendisliğinde, yüksek lisans eğitimini Eskişehir Osmangazi Üniversitesi inşaat mühendisliği ulaştırma anabilim dalında tamamlamıştır. Şuan Gaziantep Üniversitesinde doktora yapmakta ve ulaştırma anabilim dalında araştırma görevlisi olarak çalışmaktadır. İlgi alanına giren araştırma konuları kent içi ulaşım sistemleri ve ulaştırma ekonomisidir.

E-Posta: fyildizhan@gantep.edu.tr

$\mathrm{Bu}$ makalede bilimsel araştırma ve yayın etiğine uyulmuştur. 